\author{
Loyalitas Kreativitas \\ Aldi Masyarakat Kreatif
}

P-ISSN 2722-2101, E-ISSN 2722-4201

Program Studi Ekonomi Manajemen Universitas Pamulang Jurnal LOKABMAS Kreatif Vol.02,No.01,Maret 2021 Hal.93-99

Email:jurnalkreatif.manajemen@gmail.com

\title{
PENDIDIKAN DAN PELATIHAN MEMBANGUN GENERASI MUDA YANG CERDAS EMOSIONAL DAN BERKARAKTER
}

\author{
Rahadyan Tajuddien, Agung Tri Putranto, Sigit Purnomo, \\ Akhmar Barsah , Arman Syah \\ dosen01633@unpam.ac.id, agung.tputranto@gmail.com, dosen01578@unpam.ac.id, \\ dosen02152@unpam.ac.id, dosen02017@unpam.ac.id
}

\begin{abstract}
ABSTRAK
Pengabdian ini berjudul Membangun Generasi Muda Yang Cerdas secara Emosional dan Berkarakter. Kegiatan ini berlokasi pada komunitas Arimbin - Pondok Pucung, Tangerang Selatan.

Tujuan pengabdian ini adalah untuk memberikan pemahaman maupun konselling (tanya jawab) terhadap anggota Arimbin, terkait dengan pengembangan Karakter dan juga bagaimana meningkatkan kecerdasan emosional secara individu. Metode pelaksanaan pengabdian ini dilakukan dalam beberapa tahap, yaitu. 1) Tahapan pendahuluan dilakukan dengan cara merumuskan permasalahan dan juga menentukan rumusan pendekatan teori yang tepat yang berkaitan dengan objek Pengabdian Kepada Masyarakat (PKM). 2) Tahapan yang kedua adalah mengenai Sosialisasi program tersebut kepada objek PKM serta menentukan teknis dan juga pelaksanaan kegiatan tersebut. 3) Tahapan terakhir yaitu pelaksanaan kegiatan. Tahapan ini dilakukan setelah tahapan Pendahuluan dan Sosialisasi kepada Objek PKM dilakukan.

Peserta mendapatkan materi mengenai pemahaman Kecerdasan Emosional dan juga bagaimana meningkatkan karakter kebaikan pada diri remaja. Hal tersebut setelah ada tanya jawab serta diskusi mengenai materi yang telah dipaparkan pada saat sesi jawab antar narasumber dengan peserta kegiatan.
\end{abstract}

\section{Kata Kunci: Pelatihan, Pendidikan, Cerdas Emosional, Karakter, Remaja}

\section{ABSTRACT}

This activity is is entitled Building Emotional and Character Intelligent Young Generation. This activity is located in the Arimbin community - Pondok Pucung, South Tangerang.

The purpose of this service is to provide understanding and counseling (question and answer) to Arimbin members, related to character development and also how to improve individual emotional intelligence. The method of implementing this service is carried out in several stages, namely. 1) Preliminary stages are carried out by formulating problems and also determining the formulation of an appropriate theoretical approach related to the object of Community Service (PKM). 2) The second stage is regarding the 


\section{Loyalitas Kreativitas \\ Aldi Masyarakat Kreatif}

P-ISSN 2722-2101, E-ISSN 2722-4201

Program Studi Ekonomi Manajemen Universitas Pamulang Jurnal LOKABMAS Kreatif Vol.02,No.01,Maret 2021 Hal.93-99

Email:jurnalkreatif.manajemen@gmail.com

socialization of the program to PKM objects and determining the technical and implementation of these activities. 3) The last stage is the implementation of activities. This stage is carried out after the Introduction and Socialization to PKM Objects are carried out.

Participants received enlighment about understanding Emotional Intelligence and also how to improve the character of goodness and adolescents. This was after there were questions and answers and discussion about the material that was presented during the answer session between the speakers and the activity participants.

Keywords: Training, Education, Emotional Intelligent, Character, Youth

\section{PENDAHULUAN}

Remaja saat ini berada pada generasi cyber yang secara langsung maupun tidak berpengaruh pada perkembangan emosi, hubungan sosial, bahasa, nilai, moral, sikap dan lain sebagainya. Pada usia remaja, kematangan emosi individu belum stabil yang mendorong munculnya berbagai penyimpangan. Contoh bentuk penyimpangan yang terjadi saat ini yaitu senang hura-hura, senang pesta-pesta dan sebagainya sebagai nilai-nilai yang dominan dalam budaya anak muda (Sarwono : 2012) dalam (Saputra, Lestari, Milasari, \& Solikhah, 2017)

Penyimpangan selanjutnya adalah perilaku konsumtif. Perilaku membeli tidak lagi dilakukan karena produk tersebut memang dibutuhkan, tetapi karena alasan-alasan lain seperti sekedar mengikuti arus mode atau hanya ingin mencoba produk baru. Salah satu faktor penyebab terjadinya penyimpangan pada remaja adalah berkembangnya media sosial yang tidak diikuti dengan kebijaksanaan dalam pemanfaatannya.
Selanjutnya menurut Hurlock (1994) dalam (Hallatu, 2016) terkadang beberapa remaja mengabaikan peraturan dan hukum-hukum yang ditetapkan untuk dipatuhi, dan beberapa lainnya tidak mampu mempelajari apa yang benar dan apa yang salah.

Berdasarkan pemahaman di atas, dapat dipahami bagaimana pentingnya karakter dan kecerdasan emosional itu dkembangkan pada masa remaja. Diharapkan dengan adanya pemahaman mengenai Pendidikan karakter serta pengembangan kecerdasan emosional remaja dapat menganalisa serta mengatasi pelbagai masalah yang menghiasi keseharian mereka. Dan dalam jurnal ini dibahas dengan menggunakan pendekatan dari teori - teori yang dikemukan para ahli agar sesuai dengan tema maupun rumusan masalah yang berkaitan dengan ini.

\section{RUMUSAN MASALAH}

Dengan melihat latar belakang yang telah diutarakn di atas, kami berinisiatif untuk melakukan kegiatan Pengabdian Kepada Masyarakat agar dapat 


\section{Loyalitas Kreativitas P-ISSN 2722-2101, E-ISSN 2722-4201 \\ Program Studi Ekonomi Manajemen Universitas \\ Aldi Masyarakat Kreatidnulang \\ Hal.93-99 \\ Jurnal LOKABMAS Kreatif Vol.02,No.01, Maret 2021 \\ Email:jurnalkreatif.manajemen@gmail.com}

membantu dalam hal ini generasi muda (pelajar) untuk dapat mengenali kepribadian mereka dan menggali potensi-potensi serta mengembangkan hal tersebut. Penekanan pada kegiatan kali ini dilakukan pada pengembangan karakter serta kecerdasan emosional mereka.

\section{TUJUAN PELAKSANAAN}

1. Memperkenalkan pemahaman mengenai kecerdasan emosional dan bagaimana hal tersebut dibangun serta kemudian bisa dikembangkan agar dapat diaplikasikan dalam kehidupan sehari - hari.

2. Memperkenalkan dan memberikan pemahaman mengenai karakter remaja dan faktor-faktor yang dapat memperkuat hal tersebut.

\section{TINJAUAN PUSTAKA}

\section{Remaja dan Masa Remaja}

Menurut Sarwono (2004) dalam (Hallatu, 2016) Remaja berasal dari kata latin adolescere yang berarti tumbuh ke arah kematangan. Lebih lanjut dijelaskan bahwa masa remaja adalah usia dimana individu berintegrasi dengan masyarakat dewasa, berhubungan dengan masa puber dan juga perubahan intelektual. Menurut (Saputra et al., 2017) remaja juga cenderung ingin diakui sebagai anggota suatu kelompok atau diterima oleh lingkungan sosialnya. Misalnya dengan perilaku fanatik mengikuti tren yang dapat membuat para remaja merasa percaya diri dan diterima oleh lingkungan sosialnya. Remaja lebih banyak menghabiskan waktunya bersama dengan teman-teman sebaya, sehingga pengaruh teman-teman sebaya pada sikap, pembicaraan, minat, penampilan, dan perilaku lebih besar daripada pengaruh keluarganya.

Masa remaja identik dengan masamasa indah dan menyenangkan yang tidak ingin dilewatkan dengan sia-sia. Masa remaja juga identik dengan masa yang penuh kerumitan karena harus berhadapan dengan masa transisi nilai dari masa kanak-kanak beralih ke tahap dewasa (Bachri \& Suharnan, 2014).

Lebih lanjut dengan mengutip pendapat Hurlock (1987) (Bachri \& Suharnan, 2014) menjelaskan bahwa batasan masa remaja berdasarkan usia kronologis, yaitu antara usia 13 hingga 18 tahun. beberapa masalah dialami oleh remaja dalam memenuhi tugastugas perkembangan yaitu masalah pribadi, seperti misalnya masalahmasalah yang ber- hubungan dengan situasi dan kondisi di rumah, sekolah, kondisi fisik, penampilan, emosi, penyesuaian sosial, tugas dan nilainilai. Disamping itu masalah khas remaja, yaitu masalah yang timbul akibat status yang tidak jelas pada remaja, seperti masalah pencapaian kemandirian, kesalahpahaman atau penilaian berdasarkan stereotip yang keliru, adanya hak-hak yang lebih besar dan lebih sedikit kewajiban dibebankan oleh orang tua

\section{CERDAS EMOSIONAL}

Menurut Yusuf dan Nurihsan (2008) dalam (Nursari \& Hidayati, 2017) 


\section{Loyalitas Kreativitas P-ISSN 2722-2101, E-ISSN 2722-4201 \\ Program Studi Ekonomi Manajemen Universitas \\ Aldi Masyarakat Kreatiofnulang \\ Hal.93-99 \\ Jurnal LOKABMAS Kreatif Vol.02,No.01, Maret 2021 \\ Email:jurnalkreatif.manajemen@gmail.com}

Kecerdasan emosional ini merujuk kepada kemampuan-kemampuan memahami diri, mengelola emosi, memanfaatkan emosi secara produktif, empati dan membina hubungan". Kecerdasan emosi adalah kemampuankemampuan memahami diri, mengelola emosi, memotivasi diri, dan membina hubungan dengan orang lain.

Goleman (2007) dalam (Hatima, Rossanty, \& Risnawati, 2016) memaparkan bahwa kecerdasan emosional (EQ) mempunyai lima komponen atau dimensi, dan tiap komponen mempunyai beberapa Pengembangan SDM. Kelima komponen/dimensi tersebut yaitu.

1. Pengenalan Diri (self-awareness) Pengenalan diri merupakan dasar dari kecerdasan emosional, pengenalan diri adalah kemampuan untuk mengenali perasaan sendiri dan mengatur perasaan tersebut dalam cara yang dapat dikontrol, memandu pemecahan masalah, memiliki tolak ukur yang realistis atas kemampuan diri dan kepercayaan diri yang kuat

2. Pengendalian diri (self-regulation) Pengendalian diri adalah kemampuan untuk mengelola emosi sehingga emosi dapat diungkap dengan tepat, kemampuan untuk menenangkan diri dari kecemasan, kemurungan dari kemarahan yang menjadi serta mampu pulih dari tekanan emosi
3. Motivasi

(motivation)

Motivasi adalah sesuatu yang menggunakan hasrat individu yang paling dalam untuk menggerakan dan menuntun menuju sasaran, membantu mengambil inisiatif dan bertindak sangat efektif, serta untuk bertahan menghadapi kegaagalan

4. Empati

(empathy) Empati adalah kemampuan mengetahui perasaan orang lain, menyesuaikan diri terhadap apa yang diinginkan orang lain, menumbuhkan hubungan saling percaya dan menyelaraskan diri dengan bermacam-macam orang

5. Keterampilan sosial (social skills) Keterampilan sosial adalah kemahiran dalam mengubah tanggapan yang dikehendaki oleh orang lain. Diantaranya adalah kemampuan persuasi, mendengar dengan terbuka dan memberi pesan yang jelas, kemampuan menyelesaikan pendapat

\section{KARAKTER}

Menurut (Sudrajat, 2011) kata character berasal dari bahasa Yunani charassein, yang berarti to engrave (melukis, menggambar), seperti orang yang melukis kertas, memahat batu atau metal. Berakar dari pengertian yang seperti itu, character kemudian diartikan sebagai tanda atau ciri yang khusus, dan karenanya melahirkan sutu pandangan bahwa karakter adalah 'pola 


\section{Loyalitas Kreativitas P-ISSN 2722-2101, E-ISSN 2722-4201 \\ Program Studi Ekonomi Manajemen Universitas \\ Aldi Masyarakat Kreatiofnulang \\ Hal.93-99 \\ Jurnal LOKABMAS Kreatif Vol.02,No.01,Maret 2021 \\ Email:jurnalkreatif.manajemen@gmail.com}

perilaku yang bersifat individual, keadaan moral seseorang.

Lickona (2004) dalam (Situmorang, Hastuti, \& Herawati, 2016) menjelaskan bahwa karakter adalah hal yang universal dan dapat dijelaskan oleh berbagai macam aspek yang ada dalam kehidupan bermasyarakat. Karakter dapat dikatakan baik apabila yang tergambar dari diri seseorang adalah nilai-nilai atau sifat kebaikan. Kebaikan ini diterima oleh masyarakat dan diterapkan pada setiap aspek kehidupan. Lebih lanjut dijelaskan bahwa seseorang yang berkarakter adalah orang yang mengetahui kebaikan, mencintai kebaikan, serta melakukan kebaikan. Karakter yang baik merupakan sesuatu yang bisa dikembangkan dan pengembangan itu sangat mungkin dilakukan. Hal utama yang perlu dipersiapkan dalam membangun karakter seseorang adalah lingkungan yang penuh kasih sayang.

Dimensi pengukuran karakter remaja menurut Peterson dan Seligman (2004) dalam (Situmorang et al., 2016) dapat diukur dengan menggunakan pendekatan 3 (tiga) dimensi yaitu;

1. Pengetahuan moral (moral knowing) Sebuah ukuran yang berkaitan dengan pengetahuan remaja terhadap nilai-nilai kebaikan. Contoh; "kebersihan lingkungan merupakan tanggung jawab semua warga"

2. Perasaan

(feeling)

Sebuah ukuran yang berkaitan dengan perasaan remaja terhadap nilai-nilai kebaikan. Contoh; "saya merasa bertanggung jawab terhadap kebersihan lingkungan"

3. Tindakan (action) Sebuah ukuran yang berkaitan dengan tindakan remaja terhadap nilai-nilai kebaikan. Contoh; "saya akan ikut menjaga kebersihan lingkungan sekitar"

\section{METODE PELAKSANAAN}

Metode pelaksanaan ini dilakukan dalam 3 (tiga) rangkaian kegiatan, yaitu Tahapan Pendahuluan, Sosialisasi dan Pelaksanaan.

1. Tahapan pendahuluan dilakukan dengan cara merumuskan permasalahan dan juga menentukan rumusan pendekatan teori yang tepat yang berkaitan dengan objek Pengabdian Kepada Masyarakat (PKM)

2. Tahapan yang kedua adalah mengenai Sosialisasi program tersebut kepada objek PKM serta menentukan teknis dan juga pelaksanaan kegiatan tersebut.

3. Tahapan terakhir yaitu pelaksanaan kegiatan. Tahapan ini dilakukan setelah tahapan Pendahuluan dan Sosialisasi kepada Objek PKM dilakukan.

HASIL DAN PEMBAHASAN 


\section{Loyalitas Kreativitas P-ISSN 2722-2101, E-ISSN 2722-4201 \\ Aldi Masyarakat Kreatiofnulang \\ Program Studi Ekonomi Manajemen Universitas \\ Hal.93-99 \\ Jurnal LOKABMAS Kreatif Vol.02,No.01,Maret 2021 \\ Email:jurnalkreatif.manajemen@gmail.com}

Kegiatan Pengabdian Kepada

Masyarakat (PKM) adalah salah satu kegiatan Tridharma Perguruan Tinggi yang berorientasi kepada pengembangan masyarakat. Baik itu mengenai pemahaman maupun dalam bentuk program nyata yang bersinggungan dengan kehidupan sehari-hari masyarakat.

Pada kesempatan kali ini, kegiatan PKM yang dilakukan bertempat pada Objek yaitu Komunitas ARIMBIN (Anak Rimba Bintaro) yang berlokasi pada Kelurahan Pondok Pucung, Tangerang Selatan. Komunitas ARIMBIN adalah komunitas remaja Pecinta Alam yang menekankan kepada pemahaman kepada organisasi dan juga kecintaan kepada Alam. Dengan hal tersebut komunitas ini berharap dapat mengembangkan karakter dan juga meningkatkan kecerdasan emosional remaja pada umumnya.

Sejalan dengan hal tersebut, kegiatan PKM ini juga mengambil tema yaitu Membangun Generasi Muda yang Cerdas secara Emosional dan Berkarakter. Adapun kegiatan kali ini dilakukan dalam bentuk pemberian penyuluhan dan juga pembekalan materi mengenai materi yang berkaitan dengan tema kegiatan.

Kegiatan ini dilakukan pada tanggal 10 - 16 Oktober 2020. Dan berlokasi pada base camp komunitas Arimbin.

\section{KESIMPULAN DAN SARAN}

\section{Kesimpulan}

Peserta mendapatkan materi mengenai pemahaman Kecerdasan Emosional dan juga bagaimana meningkatkan karakter kebaikan pada diri remaja. Hal tersebut setelah ada tanya jawab pada saat sesi jawab antar narasumber dengan peserta kegiatan.

\section{Saran}

Kegiatan ini diharapkan bisa berkelanjutan dengan materi yang kemudian disesuaikan kebutuhan dari komunitas Arimbin itu sendiri. Harapannya mereka tidak hanya mendapatkan materi pada kegiatan kali ini saja tapi juga materi yang lain.

\section{DAFTAR PUSTAKA}

Bachri, S., \& Suharnan, S. (2014). Kecerdasan Emosi, Persepsi terhadap Pendidikan Karakter Cinta Damai dan Penyesuaian Diri Remaja. Persona:Jurnal Psikologi Indonesia, 3(01), 52-64. https://doi.org/10.30996/persona.v 3i01.369

Hallatu, T. G. R. (2016). Studi tentang Dampak Handphone terhadap Moralitas dan Karakter Remaja. Magistra, 3(1), 58-68.

Hatima, K., Rossanty, N. P. E., \& Risnawati. (2016). Pengaruh Kecerdasan Intelektual Dan Kecerdasan Emosional Terhadap Prestasi Akademik Mahasiswa Manajemen Universitas Tadulako. Jurnal Ilmu Manajemen Universitas Tadulako, 2(2), 127134. 
Email:jurnalkreatif.manajemen@gmail.com

Nursari, \& Hidayati. (2017). Hubungan Antara Kemampuan Numerik, Kecerdasan Emosi Dan Kemandirian Belajar Dengan Prestasi Belajar Fisika Siswa. Jurnal Ilmiah Pendidikan FisikaCOMPTON, 4(1), 80-90.

Saputra, S., Lestari, R. D., Milasari, M., \& Solikhah, O. H. (2017). Analisis Karakter Remaja Gaul pada Hedonisme Vlog. Mediapsi, 03(01), 26-33. https://doi.org/10.21776/ub.mps.2 017.003.01.4

Situmorang, Z. R. D., Hastuti, D., \& Herawati, T. (2016). Terhadap Karakter Remaja Perdesaan. Jurnal Ilmiah Kelekatan, Komunikasi Dan Karakter Remaja, 9(2), 113-123.

Sudrajat, A. (2011). Mengapa Pendidikan Karakter. Jurnal Pendidikan Karakter, I(1), 47-58.


https://doi.org/10.21831/jpk.v1i1. 1316

\section{DOKUMENTASI KEGIATAN}
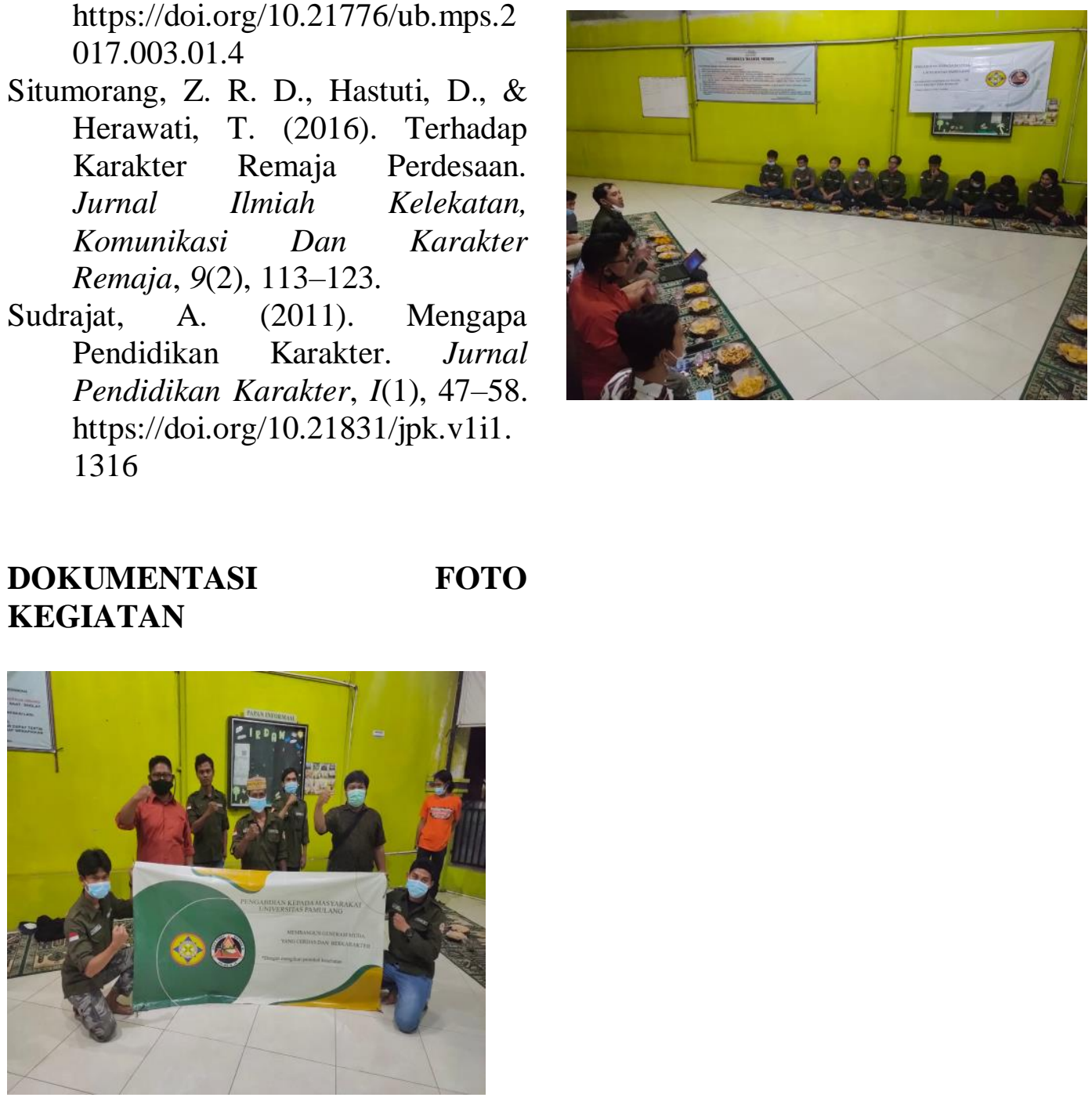